\title{
Processing and Characterization of Antibacterial Hydrogel Sheet Dressings Composed of Poly(vinyl alcohol) and Silk Fibroin for Wound Healing Application ${ }^{\dagger}$
}

\author{
Pimpon UTTAYARAT ${ }^{1, *}$, Rattanakorn CHIANGNOON ${ }^{1}$, \\ Jarurattana EAMSIRI ${ }^{1}$ and Wongwit SENAWONGSE ${ }^{2}$ \\ ${ }^{1}$ Thailand Institute of Nuclear Technology (Public Organization), Nakhon Nayok 26120, Thailand \\ ${ }^{2}$ Department of Biomedical Engineering, Srinakharinwirot University, Nakhon Nayok 26120, Thailand
}

("Corresponding author's e-mail: puttayar@gmail.com, pimponu@tint.or.th)

Received: 12 March 2018, Revised: 4 August 2018, Accepted: 26 August 2018

\begin{abstract}
Hydrogels are soft materials that contain high water content within their 3-dimensional structure. Such extremely hydrated environment allows hydrogels to recapitulate the structure of many native tissues inside the body. In biomedical application, hydrogels have been extensively used as biocompatible materials, drug delivery systems, and tissue-engineered scaffolds that can be designed to possess either permanent or slow-degradation properties. In this research, we applied gamma irradiation to develop transparent and conformal hydrogel sheets with sufficient mechanical strength from poly(vinyl alcohol) (PVA) and further modified the based PVA matrix with naturally-derived silk fibroin (SF) protein and silver nitrate $\left(\mathrm{AgNO}_{3}\right)$ for wound healing purpose. The physical and mechanical properties of based PVA hydrogels formed at varied irradiation doses from $10-80 \mathrm{kGy}$ were first characterized. The dose of 60 $\mathrm{kGy}$ was found to be optimal to process flexible and elastic PVA sheets with equilibrium degree of swelling of $1000 \%$, gel fraction of $90 \%$, and tensile strength of $19 \mathrm{kPa}$. To further enhance water absorption capacity, $10-40 \%(\mathrm{w} / \mathrm{w})$ silk fibroin was added to the based PVA matrix. Based on water absorption and gel fraction data, hydrogel sheets with 8PVA:2SF formulation was selected for antibacterial test. Disc diffusion assay showed that the incorporation of $0.4 \mathrm{mM} \mathrm{AgNO}_{3}$ in $8 \mathrm{PVA}: 2 \mathrm{SF}$ hydrogel sheets could inhibit the growth of Staphyllococcus aureus and Pseudomonas aeruginosa. These results demonstrated that a prototypic, antibacterial hydrogel sheet dressing composed of both synthetic and natural polymers could be developed within a single-step by gamma irradiation technique.
\end{abstract}

Keywords: Hydrogel sheet dressing, PVA, silk fibroin, gamma irradiation, silver nitrate

\section{Introduction}

Hydrogels are 2 component systems consisting of 3-dimensional (3D) networks of hydrophillic polymers and water that fills the space between the polymer chains [1,2]. The high water content of hydrogels gives the materials advantages in biomedical application as it contributes to biocompatible property and minimal tendency to cause irritation [3-5]. Due to the ability to imbibe and retain a lot of water within their matrices without compromising structural integrity, hydrogels have been extensively used as contact lens [1,6-8], drug delivery systems, wound dressings [1,6,8-13], and tissue-engineered scaffolds [3-5,14-17].

\footnotetext{
${ }^{\dagger}$ Presented at the International Conference on Biomedical Sciences 2018: March $22^{\text {nd }}-23^{\text {rd }}, 2018$
} 
http://wjst.wu.ac.th

Hydrogels can be formed by means of physical or chemical methods $[1,10]$. As for the second approach, ionizing radiation has long been recognized as a suitable tool for the formation of hydrogels $[1,18-20]$ that possess stable, crosslinked networks of polymer chains in the $3 \mathrm{D}$ structure. The technique offers an ease of processing control over the use of harmful chemical initiators or crosslinkers, and also an ability to combine sterilization and joining of polymer chains within a single step. Synthetic polymers such as poly(vinyl alcohol) (PVA), poly(vinyl pyrrolidone) (PVP), poly(ethylene oxide), polyacrylamide, poly(acrylic acid), and poly(vinyl methyl ether) have been extensively investigated in the formation of hydrogels by both gamma and electron beam irradiation [1,6,8,13,20-23]. In addition, natural polymers such as chitosan [2,22,24], starch [8,13], carboxy methylcellulose [25], silk [9,16,26,27], agar [12,21,28], and carrageenan [6,23] are also added to PVA- and PVP-based solutions before the blended systems are rendered crosslinked by irradiation to improve the physical and mechanical properties of the resulting hydrogels. Examples of commercial hydrogel sheet dressings fabricated by irradiation techniques are KIKgel $^{\circledR}$, Aqua-gel ${ }^{\circledR}, \mathrm{NuGel}^{\circledR}$ and HiZel ${ }^{\circledR}[6,10]$.

Among various naturally-derived polymers used in the formation of hydrogel, silk fibroin (SF) has a long track record in medicine as suture [29] as well as its excellent mechanical and biocompatible properties $[29,30]$ that makes SF as an attractive candidate in biomedical research. Many studies reported the use of silk fibroin in wound dressings [31-34], artificial skin substitutes [26], synthetic vascular grafts [30,35], drug delivery system [36,37], and tissue-engineered scaffolds [16,27,30]. For wound healing application, in vivo studies showed that SF-based dressings could promote the healing of full-thickness wounds with minimal inflammatory response in rat and mice models [31,33]. Among various fabrication techniques, gamma irradiation is utilized in the processing of SF and SF-blended PVA hydrogels for tissue-engineered scaffold [16] and artificial skin substitute [26], respectively. The SF hydrogels formed by irradiationinduced crosslinking showed an increase in mechanical strength to withstand compressive load compared to those prepared by physical entanglement of SF, and also were cytocompatible with human mesenchymal stem cells [16]. In addition, the complete transformation of random coils to beta-sheets in the SF structure was reported in SF-blended PVA hydrogels at elevated irradiation doses up to 40 and $50 \mathrm{kGy}$ [26].

\section{Materials and methods}

\section{Chemicals and reagents}

All chemicals including PVA $\left(\mathrm{M}_{\mathrm{w}} 89,000\right.$ - 98,000), calcium chloride $\left(\mathrm{CaCl}_{2}\right)$, sodium carbonate $\left(\mathrm{Na}_{2} \mathrm{CO}_{3}\right)$, and silver nitrate $\left(\mathrm{AgNO}_{3}\right)$ were purchased from Sigma Aldrich (St. Louise, USA). Cocoons of Thai silkworms B. mori (variant Nangnoi Si Sa Ket) were obtained from the Chiang Mai Sericulture Center (Chiang Mai, Thailand). Silk fibroin protein was extracted from the as-received cocoons using the previously described method [39]. Reversed osmosis (RO) water was used in all experiments.

\section{Preparation of PVA and SF-PVA hydrogel sheets}

A solution of $10 \%(\mathrm{w} / \mathrm{v})$ PVA was prepared by dissolving PVA powder in hot water for 30 min and then mixed thoroughly by magnetic stirrer for $1 \mathrm{~h}$. After the solution was cooled to room temperature (RT), it was deaerated with $\mathrm{N}_{2}$ gas for $30 \mathrm{~min}$ before being transferred to $100 \times 100 \mathrm{~mm}^{2}$ square petri dishes. Each sample was sealed inside a plastic bag and then exposed to gamma irradiation at doses of 10 , 25, 40, 60 and $80 \mathrm{kGy}$ at the Gem Irradiation Center facility, Thailand Institute of Nuclear Technology (Public Organization). As a control, the starting PVA solution was left to form dried films inside the petri dishes at RT.

For the formation of PVA/SF hydrogel sheets, lyophilized SF protein was added to PVA solution at varied concentrations from $10-40 \mathrm{wt} \%$ while the PVA content in the final solution was made up to 100 $\mathrm{wt} \%$. After thorough mixing, the solution was transferred to circular 50-mm diameter molds and crosslinked by gamma irradiation.

\section{Water absorption properties of hydrogels}

After the irradiation process, hydrogel samples were washed 3 times, 10 min each, with RO water on a rotator at $60 \mathrm{rpm}$ to remove unreacted molecules before being cut into $3 \times 3 \mathrm{~cm}^{2}$ samples. To simulate 
http://wjst.wu.ac.th

the ability of gel sheets to absorb exudate at wound site (adapted from European Standard EN 13726), the samples were immersed in an aqueous solution containing $145 \mathrm{mmol} \mathrm{NaCl}$ and $2.5 \mathrm{mmol} \mathrm{CaCl}_{2}$ (solution A). The increase in water uptake was calculated by the following equation.

water uptake ratio $=\mathrm{W}_{\mathrm{s}} / \mathrm{W}_{\mathrm{i}}$

where $\mathrm{W}_{\mathrm{s}}$ was the swollen weight and $\mathrm{W}_{\mathrm{i}}$ was the initial weight of hydrogels.

For swelling kinetics of hydrogels, selected samples were immersed in solution A for the entire duration of $72 \mathrm{~h}$, and the swollen weight was recorded at 5, 15,30 and $60 \mathrm{~min}$, and then at $72 \mathrm{~h}$. After the termination of water absorption at specified time point, all samples were dried to a constant weight at 60 ${ }^{\circ} \mathrm{C}$. Then the equilibrium degree of swelling (EDS) was calculated as;

$\operatorname{EDS}(\%)=\mathrm{W}_{\mathrm{s}} / \mathrm{W}_{\mathrm{d}}$

where $\mathrm{W}_{\mathrm{s}}$ was the swollen weight and $\mathrm{W}_{\mathrm{d}}$ was the dried weight.

\section{Gel fraction}

Hydrogel samples were placed in glass tubes filled with RO water and boiled for 15 min to extract the loose, non-crosslinked polymeric molecules. The remaining gel portion was dried to a constant weight at $60{ }^{\circ} \mathrm{C}$. Gel fraction was then measured gravimetrically according to the following equation;

Gel fraction $(\%)=\mathrm{W}_{\mathrm{f}} / \mathrm{W}_{\mathrm{o}}$

where $\mathrm{W}_{\mathrm{f}}$ was the final dried weight and $\mathrm{W}_{\mathrm{o}}$ was the initial dried weight.

\section{Mechanical properties of hydrogels}

To estimate the mechanical properties of crosslinked hydrogels, the irradiated samples were examined by both tensile and compression tests. Tensile strength and elongation at break were measured by Lloyd LS1 (Ametek (GB) Ltd, UK) on rectangular gel samples $\left(1 \times 4 \mathrm{~cm}^{2}\right)$ at a crosshead speed of 50 $\mathrm{mm} / \mathrm{min}$.

For the analysis of gel strength, samples were prepared into disc shape with diameter 35 or $50 \mathrm{~mm}$, and thickness of $\sim 3-4 \mathrm{~mm}$. All hydrogel samples were kept in hydrated environment until ready to be used. The samples were placed between a parallel plate apparatus and tested under uniaxial compression on Lloyd LS1 using a $50 \mathrm{~N}$ load cell that was set to compress the samples to $70 \%$ gel thickness at a speed of $5 \mathrm{~mm} / \mathrm{min}$.

FTIR analysis of SF-PVA hydrogels

The PVA/SF hydrogels were lyophilized and pulverized. Infrared spectra of the gel samples were collected by attenuated total reflectance Fourier transform infrared (ATR-FTIR) spectroscopy (Tensor 27, Brucker Optics, Germany) under absorbance mode from $4000-400 \mathrm{~cm}^{-1}$ at $4 \mathrm{~cm}^{-1}$ scan resolution. The starting PVA and silk fibroin powder was used as control.

\section{Disc diffusion assay}

Selected PVA/SF formulation was further incorporated with $0.4-2.0 \mathrm{mM} \mathrm{AgNO}_{3}$ during the irradiation process. The resulting hydrogel sheets were cut into $8 \mathrm{~mm}$ diameter discs and placed onto Mueller-Hinton agar plates inoculated with $10^{6}$ colony forming unit $(\mathrm{CFU}) / \mathrm{ml}$ of either $S$. aureus or $P$. aeruginosa. After $18 \mathrm{~h}$ incubation at $37{ }^{\circ} \mathrm{C}$, digital images of the inhibited areas of bacterial growth surrounding each sample were recorded and measured. 
http://wjst.wu.ac.th

\section{Data analysis}

For the analysis of water absorption, gel fraction, and tensile strength, data were collected from 3 different experiments. In terms of gel strength, data were collected from about $4-5$ samples. For the antibacterial test, disc diffusion was performed in triplicates. Data were expressed as mean \pm standard error of mean unless otherwise stated.

\section{Results and discussion}

\section{Formation of based PVA hydrogel sheets}

When a polymer solution is exposed to ionizing radiation, hydroxyl radicals $(\bullet \mathrm{OH})$ generated by radiolysis of water serves as the main reactive species that abstract hydrogen atoms off the polymer chains, thus initiating the joining or scission of these macromolecules $[18,19]$. During the joining process in which radicals on different chains recombine, the resulting intermolecular crosslinking can successfully contribute to the formation of $3 \mathrm{D}$ network that provides the structure of hydrogel. This usually requires the polymer concentration to be high enough above hydrodynamic concentration to enable the overlapping of polymer chains, which in turn increases the probability of intermolecular joining process [19]. In our PVA-based hydrogel system, the starting $10 \%$ PVA solution could form gel with thicknesses $\sim 2.0$ - $2.5 \mathrm{~mm}$ after exposed to gamma irradiation as shown in Figure 1.

With the experimental conditions we had in this study, the irradiation doses of 40 and $60 \mathrm{kGy}$ were found to be optimal for the formation of flexible and elastic hydrogels that were capable of retaining the flat sheet structure without being distorted. These PVA concentration and irradiation doses used in our system to fabricate hydrogel sheets were similar to previous studies [8,22] that reported the use of $10 \%$ PVA solution to form hydrogels by e-beam irradiation at doses 40 - $50 \mathrm{kGy}$. At lower doses, the resulting sheets became too soft and easily rolled or folded into irregular shape. In particular, less than $20 \%$ of the starting PVA solution was crosslinked and formed the sheet structure at $10 \mathrm{kGy}$. At the highest irradiation dose of $80 \mathrm{kGy}$, the hydrogel sheets lost their flexibility and were prone to break while being released off the mold. In contrast to these hydrogel sheets crosslinked by gamma irradiation, the as-cast PVA films formed at RT were shown to be rigid, stiff, and not pliable.
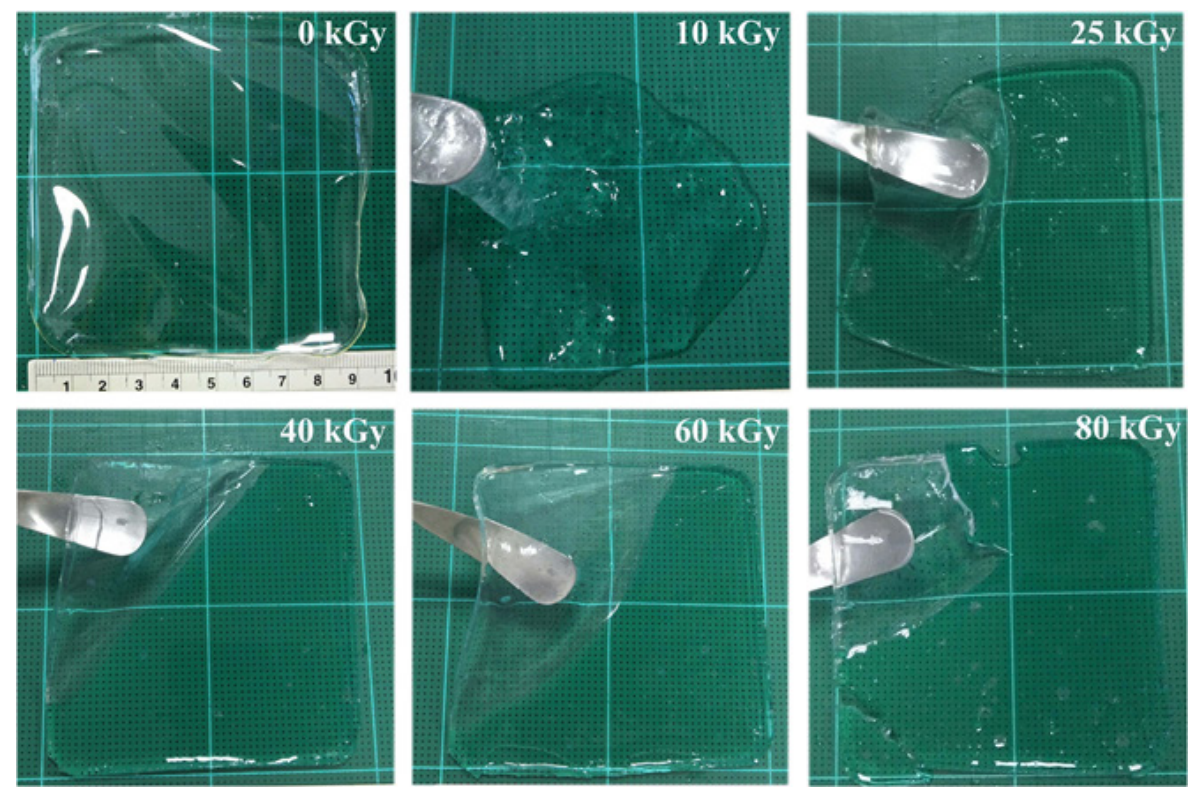

Figure 1 PVA hydrogel sheets formed at different irradiation doses from 10 - 80 kGy with as-cast, nonirradiated sheet $(0 \mathrm{kGy})$ served as a control. 
http://wjst.wu.ac.th

\section{Water absorption ability of PVA hydrogels}

The ability of hydrogel sheets to uptake additional water into their hydrated matrices was monitored as a function of time. As presented in Figure 2, PVA gel sheets crosslinked at $40 \mathrm{kGy}$ showed a rapid increase in water uptake during the first hour of immersion in solution A before reaching a steady level after $24 \mathrm{~h}$. The initial rise in swelling of hydrogel matrix can be attributed to the -OH functional group on PVA and spaces enclosed by crosslinked network that can attract and accommodate water molecules. As the elastic retraction force of the 3D network opposes, swelling eventually reaches equilibrium [10]. Therefore, the $24 \mathrm{~h}$ time point was chosen as the saturation, or equilibrium, point of swelling in our study based on this kinetics data. This time point was also within the same range compared to other hydrogel systems previously reported in the literature $[40,44,45]$.

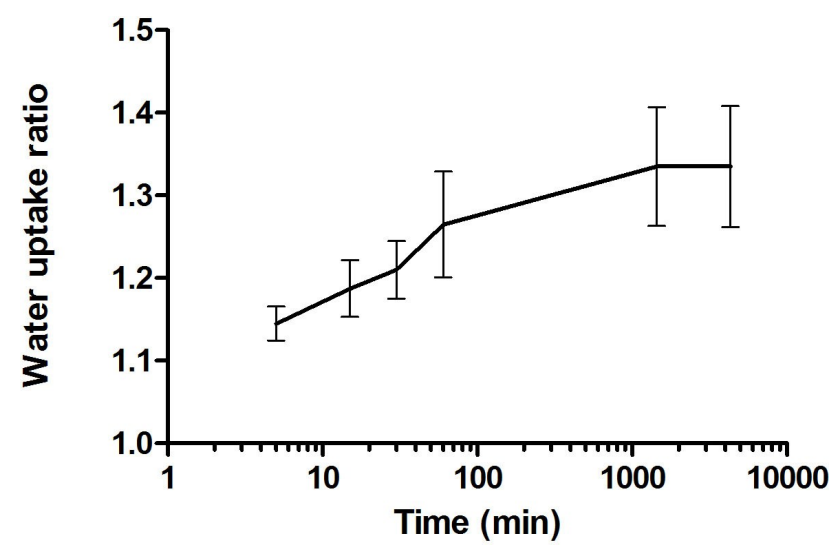

Figure 2. The swelling kinetics of crosslinked $10 \%$ PVA hydrogel sheets formed at $40 \mathrm{kGy}$.

The equilibrium degree of swelling of hydrogel sheets prepared at different irradiation doses is shown in Figure 3A. As the doses were raised from $25-80 \mathrm{kGy}$, the swelling of hydrogel sheets decreased from $\sim 2,200$ to $1,000 \%$ before reaching a steady level at doses $\geq 40 \mathrm{kGy}$. This reduction in water absorption observed in our system is in agreement with other PVA and PVP systems previously reported $[40,45]$. The smaller mesh size of $3 \mathrm{D}$ network to accommodate water molecules caused by the increase in crosslink density can be responsible for the reduction in water absorption at high doses.
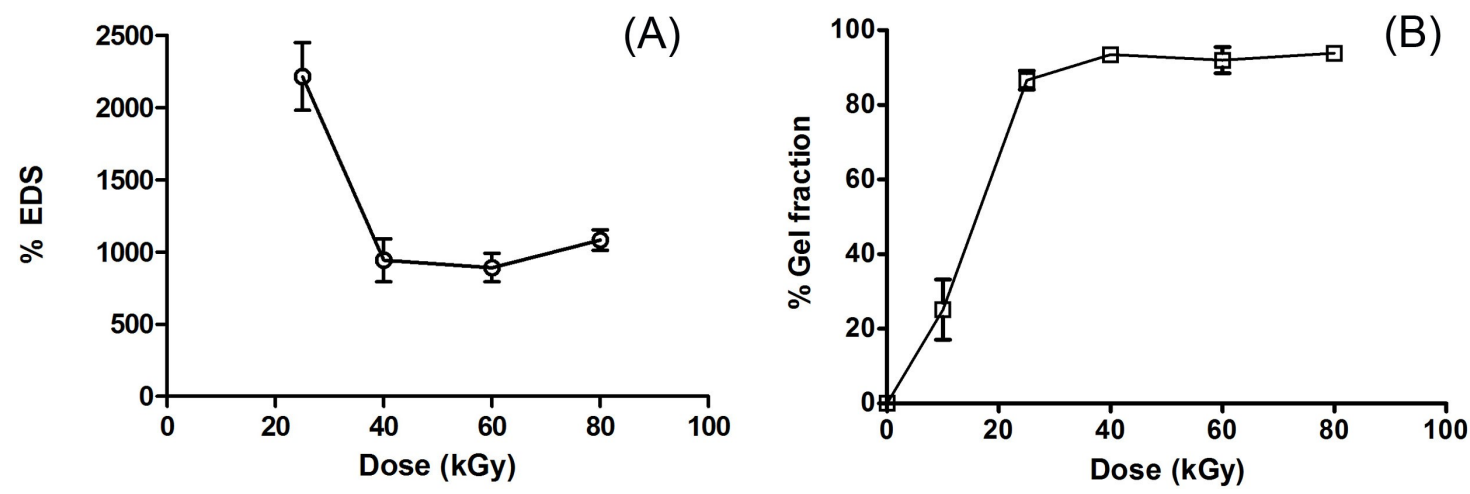

Figure 3 (A) Swelling behavior and (B) gel fraction of hydrogel sheets formed at varied irradiation doses. 
http://wjst.wu.ac.th

\section{Gel fraction}

The content of stable 3D network formed by radiation-induced crosslinking was characterized and represented by gel fraction as shown in Figure 3B. In contrast to swelling, gel fraction increased with irradiation doses from 10 to $40 \mathrm{kGy}$ before reaching a steady level of $\sim 90 \%$. This maximum extent of gel fraction of our PVA system obtained at irradiation dose $\geq 40 \mathrm{kGy}$ is within the same range as other PVAbased hydrogels reported in the literature $[8,22,40]$. As a control, the as-cast PVA films did not contain any chemical crosslinked network within the structure and were dissolved in boiling water. Based on water absorption and gel fraction data, the structural characteristics of hydrogel network is strongly affected by crosslink density, which can be controlled by irradiation dose. In our system, the doses of 40 $60 \mathrm{kGy}$ seemed to be the optimal dose range that provided flexible and elastic hydrogel sheets with the highest degree of gel fraction.

\section{Mechanical properties of PVA hydrogels}

Gel strength was measured at $70 \%$ gel depth and represented by compressive loads as shown in Table 1. The ability of hydrogels to withstand compressive load continued to increase with irradiation dose from 25 - $60 \mathrm{kGy}$. At the highest dose of $80 \mathrm{kGy}$, gel strength decreased slightly, which could be caused by degradation of PVA molecules that prevailed crosslinking. This lowered gel strength was also in agreement with our observation shown in Figure 1.

Table 1 Mechanical properties of hydrogels formed at varied irradiation doses.

\begin{tabular}{ccccc}
\hline $\begin{array}{c}\text { Dose } \\
(\mathbf{k G y})\end{array}$ & $\begin{array}{c}\text { Compressive load } \\
\mathbf{( N )}\end{array}$ & $\begin{array}{c}\text { Tensile strength } \\
\mathbf{( k P a )}\end{array}$ & $\begin{array}{c}\text { Elongation at break } \\
\mathbf{( \% )}\end{array}$ & $\begin{array}{c}\text { Young's modulus } \\
\mathbf{( k P a )}\end{array}$ \\
\hline 25 & $3.4 \pm 0.8$ & $\mathrm{n} / \mathrm{a}$ & $\mathrm{n} / \mathrm{a}$ & $\mathrm{n} / \mathrm{a}$ \\
40 & $12.4 \pm 2.0$ & $8.2 \pm 1.9$ & $89.5 \pm 23.1$ & $7.7 \pm 3.4$ \\
60 & $18.0 \pm 2.4$ & $18.8 \pm 4.7$ & $128.4 \pm 33.8$ & $10.2 \pm 3.4$ \\
80 & $12.6 \pm 0.8$ & $19.4 \pm 4.3$ & $79.3 \pm 30.2$ & $23.1 \pm 10.0$ \\
\hline
\end{tabular}

For the analysis of tensile strength, only the gel sheets formed at 40 - $80 \mathrm{kGy}$ were tested under tension as the sheets formed at $25 \mathrm{kGy}$ were too soft and easily torn during the test setup. Similar to gel strength, tensile strength and elongation at break increased as irradiation dose was raised from 40 to 60 $\mathrm{kGy}$. At $80 \mathrm{kGy}$, the elongation at break was largely reduced. Based on these data obtained from both tensile and compression tests as well as water absorption and gel fraction, the dose of $60 \mathrm{kGy}$ seemed to be best for the preparation of hydrogel sheets with optimal physical properties and mechanical strength. Therefore, we selected the dose of $60 \mathrm{kGy}$ to further fabricate PVA/SF hydrogels.

\section{Structural characteristics of PVA-SF hydrogels}

Various natural polymers, especially polysaccharides $[6,8,22,23,45]$, have been used to blend with synthetic polymers to improve both physical and mechanical properties of the resulting irradiated hydrogels. In this study, we chose SF protein extracted from the cocoons of silkworm to blend with based PVA hydrogel system. Changes in water absorption properties and content of stable 3D crosslinked network were characterized by water uptake ratio and gel fraction as shown in Figure 4. 
http://wjst.wu.ac.th
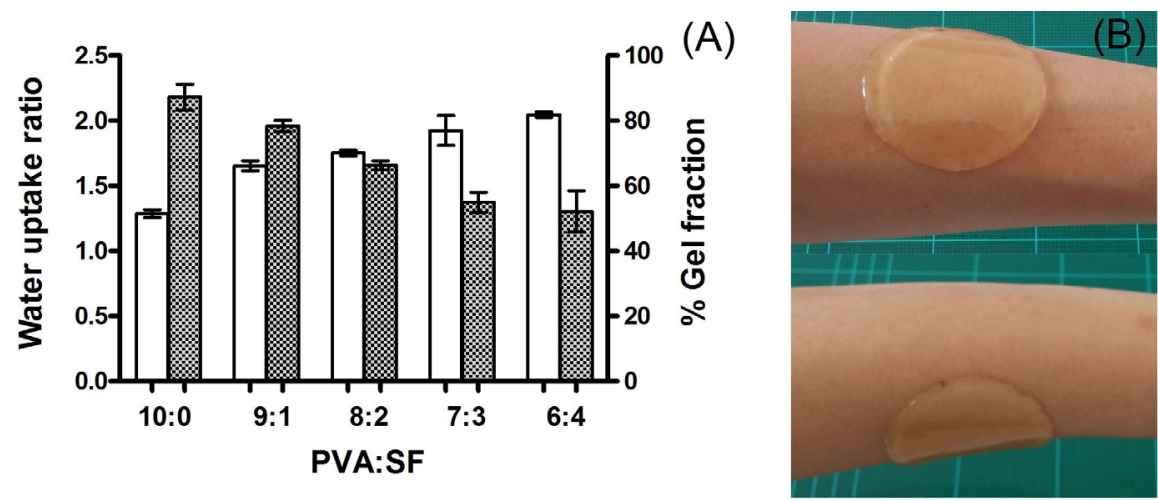

Figure 4 (A) Swelling behavior (solid white) and gel fraction (patterned gray) of blended PVA/SF hydrogel systems at varied SF proportion from $0-4 \%(\mathrm{w} / \mathrm{w})$. (B) The hydrating, flexible and conformal blended hydrogel sheet fabricated from 8PVA:2SF formulation at $60 \mathrm{kGy}$.

With the increase in SF proportion from $10-40 \%(\mathrm{w} / \mathrm{w})$, the ability of blended PVA-SF hydrogels to uptake additional water was enhanced from 1.3 to 2.0 , whereas the content of stable crosslinked network decreased by $\sim 20 \%$. Thus, the main crosslinked network is largely contributed by PVA molecules, while SF molecules may be grafted on PVA chains, similar to the PVA-chitosan blend system [22]. So functional groups such as $-\mathrm{COOH}$ and $-\mathrm{NH}_{2}$ of the side chains on $\mathrm{SF}$ molecules can attract additional water molecules. In addition, the proportion of SF beyond $20 \%(\mathrm{w} / \mathrm{w})$ also made gel sheets to become too soft, and easily folded. Therefore, the 8PVA:2SF blend system was the optimal formulation that provided a flexible and conformal gel sheet (Figure 4B) with improved water absorption property.

\section{Chemical analysis of PVA/SF hydrogels}

Figure 5 shows FTIR spectra of 8PVA:2SF hydrogel in comparison to the starting PVA and SF components. The vibration signals of $\mathrm{O}-\mathrm{H}$ and $\mathrm{C}-\mathrm{H}$ from alkyl groups of PVA could be seen at 3550 3200 and $3000-2840 \mathrm{~cm}^{-1}$, respectively, similar to the findings on blended PVA hydrogel system previously reported in literature [46]. In addition, the N-H bending vibration intensity of $\beta$-sheets in SF protein [39] could also be detected at 1650 - 1610 and $1540-1500 \mathrm{~cm}^{-1}$. These chemical signals confirmed the presence of both PVA and SF in the blended hydrogels after irradiation process.

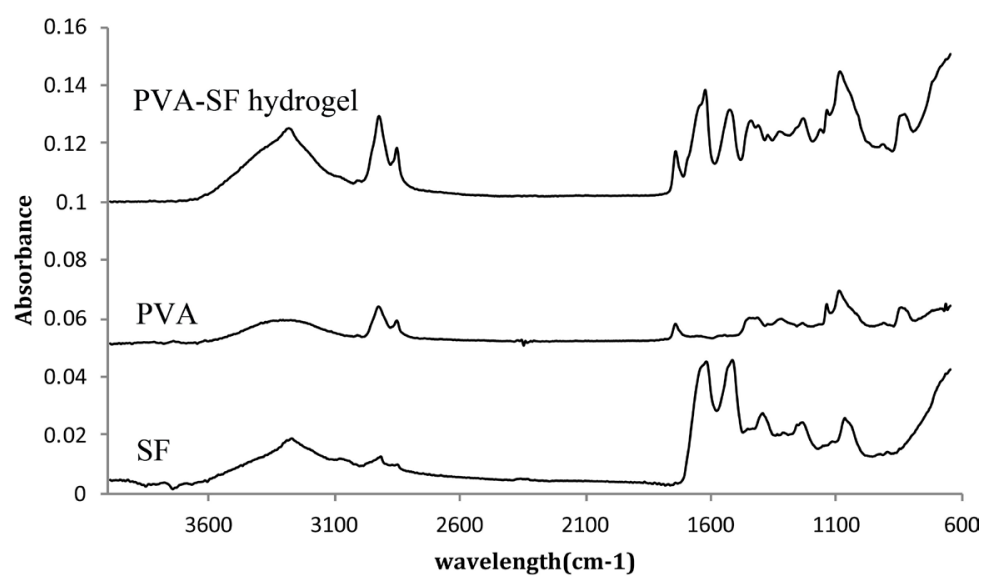

Figure 5 FTIR spectra of blended 8PVA:2SF hydrogel formed by irradiation compared to the starting PVA and SF powder. 
http://wjst.wu.ac.th

\section{Antibacterial properties}

Irradiation of silver compound in aqueous solution during the formation of hydrogel was shown to induce the formation of small $\mathrm{Ag}^{+}$clusters that conferred hydrogel matrix with antibacterial properties [40]. The binding of these $\mathrm{Ag}^{+}$clusters to proteins and DNA of bacteria leads to the disruption of cell and organelle membranes as well as DNA that eventually result in cell death [38,39,41]. In our study, we used disc diffusion assay to evaluate the antibacterial properties of 8PVA:2SF hydrogel sheets incorporated with $\mathrm{AgNO}_{3}$. Our results showed that the minimal concentration of $\mathrm{AgNO}_{3}$ at $0.4 \mathrm{mM}$ could inhibit the growth of both $S$. aureus and $P$. aeruginosa as evidenced by the formation of a clear zone as shown in Figure 6. This concentration was within the same range of what has been previously reported [39]. In addition, the inhibition ratios [39], defined as the diameter of the clear zone normalized by the diameter of hydrogel, was calculated to be $2.15 \pm 0.19$ for $S$. aureus inoculated plates and $1.35 \pm 0.04$ for $P$. aeruginosa plates. These inhibition ratios we obtained in the present study followed the similar trend with values previously reported [39] as the clear zones around hydrogel samples on $S$. aureus inoculated plates were larger than those on aeruginosa plates. In addition, the diameter of clear zone, $\sim 10 \mathrm{~mm}$, formed around our AgNP-embedded hydrogel, $7.5 \mathrm{~mm}$, against $P$. aeruginosa was within the same range as the values obtained from commercial dressings and also other hydrogel systems containing AgNPs [43].
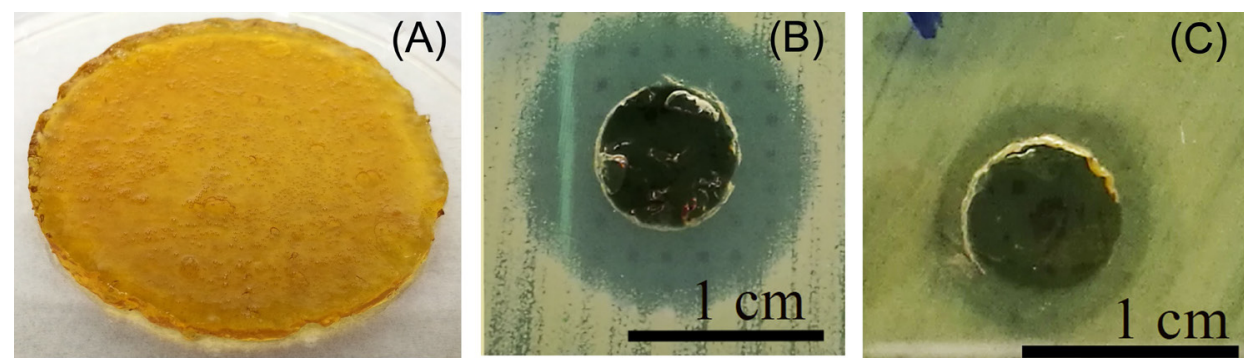

Figure 6 Digital images showing (A) 8PVA:2SF hydrogel sheet incorporated with $0.4 \mathrm{mM} \mathrm{AgNO}$, and the formation of clear zone on agar plates inoculated with (B) S. aureus and (C) P. aeruginosa.

\section{Conclusions}

In this study, we have demonstrated the feasibility of applying gamma radiation to fabricate hydrogel sheet dressings composed of multiple components as well as active ingredient in a single-step method. To maintain the mechanical strength of sheet dressings, PVA was needed as the major based component, whereas naturally-derived SF could be further added at the maximum of $20 \%$ weight content to enhance water absorption property of hydrogel sheets. The incorporation of antiseptic $\mathrm{AgNO}_{3}$ into PVA/SF blend during irradiation could effectively confer the sheet with antibacterial properties. Therefore, this prototypic antibacterial hydrogel sheet dressing can be further developed for the potential use in clinics.

\section{Acknowledgements}

This research was sponsored by the Thailand Institute of Nuclear Technology (Public Organization) (TINT). The authors would like to thank staff members at the Gem Irradiation Center and Nuclear Technology Service Center at TINT for their help on the irradiation process. Assistants to some of the experiments by Ms. Kanchana Meeruangchai, Ms. Jidapa Nacharoen, Ms. Natchaya Saosuwan, and Ms. Nattaya Chaimongkol were also acknowledged. 
http://wjst.wu.ac.th

\section{References}

[1] JM Rosiak and P Ulański. Synthesis of hydrogels by irradiation of polymers in aqueous solution. Radiat. Phys. Chem. 1999; 55, 139-51.

[2] YC Nho and KR Park. Preparation and properties of PVA/PVP hydrogels containing chitosan by radiation. J. Appl. Polym. Sci. 2002; 86, 1787-94.

[3] BJ Dekosky, NH Dormer, GC Ingavle, CH Roatch, J Lomakin, MS Detamore and SH Gehrke. Hierarchically designed agarose and poly(ethylene glycol) interpenetrating network hydrogels for cartilage tissue engineering. Tissue Eng. Part C 2010; 16, 1533-42.

[4] NE Fedorovich, MH Oudshoorn, DV Geemen, WE Hennink, J Alblas and WJA Dhert. The effect of photopolymerization on stem cells embedded in hydrogels. Biomaterials 2009; 30, 344-53.

[5] GD Nicodemus and SJ Bryant. Cell encapsulation in biodegradable hydrogels for tissue engineering applications. Tissue Eng. Part B 2008; 14, 149-65.

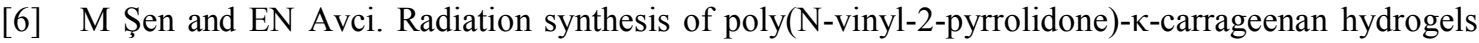
and their use in wound dressing applications. I. Preliminary laboratory tests. J. Biomed. Mater. Res. Part A 2005; 74, 187-96.

[7] F Yoshii, Y Zhanshan, K Isobe, K Shinozaki and K Makuuchi. Electron beam crosslinked PEO and PEO/PVA hydrogels for wound dressing. Radiat. Phys. Chem. 1999; 55, 133-8.

[8] M Zhai, F Yoshii, T Kume and K Hashim. Syntheses of PVA/starch grafted hydrogels by irradiation. Carbohydr. Polym. 2002; 50, 295-303.

[9] M Haji-Saeid, A Safrany, MHO Sampab and N Ramamoorthy. Radiation processing of natural polymers: The IAEA contribution. Radiat. Phys. Chem. 2010; 79, 255-60.

[10] JM Rosiak and F Yoshii. Hydrogels and their medical applications. Nucl. Instrum. Meth. Phys. Res. Sect. B 1999; 151, 56-64.

[11] K Swaroop, S Francis and HM Somashekarappa. Gamma irradiation synthesis of Ag/PVA hydrogels and its antibacterial activity. Mater. Today Proc. 2016; 3, 1792-8.

[12] MR Reneque, AR Rodriguez and CP Covas. Hydrogel wound dressing preparation at laboratory scale by using electron beam and gamma radiation. Nucleus 2013; 53, 24-31.

[13] K Hashim, KHZM Dahlan, K Bahari, F Yoshii and T Kume. Development of sago starch hydrogel for wound dressing. In: Proceedings of the Takasaki Symposium on Radiation Processing of Natural Polymers. Gunma, Japan, 2001, p. 66-74.

[14] P Uttayarat, $\mathrm{K}$ Boonsirichai, $\mathrm{T}$ Tangthong, $\mathrm{P}$ Pimton, $\mathrm{S}$ Thongbopit and $\mathrm{T}$ Phermthai. Photopolymerization of hydrogels for cartilage tissue engineering. In: Proceedings of the $8^{\text {th }}$ Biomedical Engineering International Conference 2015. Pattaya, Thailand, 2015, p. 15-7.

[15] P Uttayarat, K Boonsirichai, J Eamsiri, S Chookaew, P Pimton, P Charoonrut, P Songprakhon, P Pokathikorn, S Thongbopit, T Phermthai and S Julavijitphong. Evaluation of photopolymerizable hydrogel/stem cell constructs in vivo for cartilage tissue engineering. In: Proceedings of the $9^{\text {th }}$ Biomedical Engineering International Conference 2016. Laung Prabang, Laos, 2016, p. 3-6.

[16] MH Kim and WH Park. Chemically cross-linked silk fibroin hydrogel with enhanced elastic properties, biodegradability, and biocompatibility. Int. J. Nanomed. 2016; 29, 67-78.

[17] JM Lee, T Sultan, SH Kim, V Kumar, YK Yeon, OJ Lee and C Park. Artificial auricular cartilage using silk fibroin and polyvinyl alcohol hydrogel. Int. J. Mol. Sci. 2017; 18, 1707.

[18] K Makuuchi and S Cheng. Radiation Processing of Polymer Materials and Its Industrial Applications. John Wiley \& Sons, Hoboken, 2012.

[19] JM Rosiak, I Janik, S Kadlubowski, M Kozicki, P Kujawa and PU Stasica. Radiation Synthesis and Modification of Polymers for Biomedical Applications. International Atomic Energy Agency, Vienna, 2002.

[20] KR Park and YC Nho. Synthesis of PVA/PVP hydrogels having two-layer by radiation and their physical properties. Radiat. Phys. Chem. 2003; 67, 361-5.

[21] S Benamer, M Mahlous, A Boukrif, B Mansouri and SL Youcef. Synthesis and characterisation of hydrogels based on poly(vinyl pyrrolidone). Nucl. Instrum. Meth. Phys. Res. Sect. B 2006; 248, 28490. 
http://wjst.wu.ac.th

[22] L Zhao, H Mitomo, M Zhai, F Yoshii, N Nagasawa and T Kume. Synthesis of antibacterial PVA/CM- chitosan blend hydrogels with electron beam irradiation. Carbohydr. Polym. 2003; 53, 439-46.

[23] C Tranquilan-Aranilla, F Yoshii, AMD Rosa and K Makuuchi. Kappa-carrageenan-polyethylene oxide hydrogel blends prepared by gamma irradiation. Radiat. Phys. Chem. 1999; 55, 127-31.

[24] EA Kamoun, X Chen, MSM Eldin and ERS Kenawy. Crosslinked poly(vinyl alcohol) hydrogels for wound dressing applications: A review of remarkably blended polymers. Arab. J. Chem. 2015; 8, 114.

[25] M Wang, L Xu, H Hu, M Zhai, J Peng, Y Nho, J Li and G Wei. Radiation synthesis of PVP/CMC hydrogels as wound dressing. Nucl. Instrum. Meth. Phys. Res. Sect. B 2007; 265, 385-9.

[26] P Intavisade and B Oonkhanond. A study of irradiated silk fibroin-poly vinyl alcohol hydrogel for artificial skin substitutes. J. Met. Mater. Miner. 2010; 20, 119-22.

[27] MH Kim, BS Kim, J Lee, D Cho, OH Kwon and WH Park. Silk fibroin/hydroxyapatite composite hydrogel induced by gamma-ray irradiation for bone tissue engineering. Biomater. Res. 2017; 21, 12.

[28] L Varshney. Role of natural polysaccharides in radiation formation of PVA-hydrogel wound dressing. Nucl. Instrum. Meth. Phys. Res. Sect B 2007; 255, 343-9.

[29] GH Altman, F Diaz, C Jakuba, T Calabro, RL Horan, J Chen, H Lu, J Richmond and DL Kaplan. Silk-based biomaterials. Biomaterials 2003; 24, 401-16.

[30] B Kundu, R Rajkhowa, SC Kundu and X Wang. Silk fibroin biomaterials for tissue regenerations. Adv. Drug Deliv. Rev. 2013; 65, 457-70.

[31] A Sugihara, K Sugiura, H Morita, T Ninagawa, K Tubouchi, R Tobe, M Izumiya, T Horio, NG Abraham and S Ikehara. Promotive effects of a silk film on epidermal recovery from full-thickness skin wounds. Proc. Soc. Exp. Biol. Med. 2000; 225, 58-64.

[32] H Kweon, J Yeo, K Lee, HC Lee, HS Na, YH Won and CS Cho. Semi-interpenetrating polymer networks composed of silk fibroin and poly(ethylene glycol) for wound dressing. Biomed. Mater. 2008; 3, 34115-5.

[33] DH Roh, SY Kang, JY Kim, YB Kwon, HY Kweon, KG Lee, YH Park, RM Baek, CY Heo, J Choe and $\mathrm{JH}$ Lee. Wound healing effect of silk fibroin/alginate-blended sponge in full thickness skin defect of rat. J. Mater. Sci. Mater. Med. 2006; 17, 547-52.

[34] A Vasconcelos, AC Gomes and A Cavaco-Paulo. Novel silk fibroin/elastin wound dressings. Acta Biomater. 2012; 8, 3049-60.

[35] L Soffer, X Wang, X Zhang, J Kluge, L Dorfmann, DL Kaplan and G Leisk. Silk-based electrospun tubular scaffolds for tissue-engineered vascular grafts. J. Biomater. Sci. Polym. Ed. 2009; 19, 65364.

[36] E Wenk, AJ Wandrey, HP Merkle and L Meinel. Silk fibroin spheres as a platform for controlled drug delivery. J. Control Release 2008; 132, 26-34.

[37] L Uebersax, M Mattotti, M Papaloïzos, HP Merkle, B Gander and L Meinel. Silk fibroin matrices for the controlled release of nerve growth factor (NGF). Biomaterials 2007; 28, 4449-60.

[38] P Uttayarat, J Eamsiri, T Tangthong and P Suwanmala. Radiolytic synthesis of colloidal silver nanoparticles for antibacterial wound dressings. Adv. Mater. Sci. Eng. 2015; 2015, 376082.

[39] P Uttayarat, S Jetawattana, P Suwanmala, J Eamsiri, T Tangthong and S Pongpat. Antimicrobial electrospun silk fibroin mats with silver nanoparticles for wound dressing application. Fibers Polym. 2012; 13, 999-1006.

[40] M Kumar, L Varshney and S Francis. Radiolytic formation of Ag clusters in aqueous polyvinyl alcohol solution and hydrogel matrix. Radiat. Phys. Chem. 2005; 73, $21-7$.

[41] I Sondi and B Salopek-Sondi. Silver nanoparticles as antimicrobial agent: A case study on E. coli as a model for Gram-negative bacteria. J. Colloid Interf. Sci. 2004; 275, 177-82.

[42] R Li, J Chen, TC Cesario, X Wang, JS Yuan and PM Rentzepis. Synergistic reaction of silver nitrate, silver nanoparticles, and methylene blue against bacteria. Proc. Natl. Acad. Sci. 2016; 113, 13612-7.

[43] B Boonkaew, M Kempf, R Kimble, P Supaphol and L Cuttle. Antimicrobial efficacy of a novel silver hydrogel dressing compared to two common silver burn wound dressings: Acticoat ${ }^{\mathrm{TM}}$ and 
http://wjst.wu.ac.th

PolyMem Silver®. Burns 2014; 40, 89-96.

[44] D Parsons, PG Bowler, V Myles and S Jones. Silver antimicrobial dressings in wound management: A comparison of antibacterial, physical, and chemical characteristics. Wounds 2005; 17, 222-32.

[45] Z Ajji, I Othman and JM Rosiak. Production of hydrogel wound dressings using gamma radiation. Nucl. Instrum. Meth. Phys. Res. Sect. B 2005; 229, 375-80.

[46] MT Razzak, D Darwis, Zainuddin and Sukirno. Irradiation of polyvinyl alcohol and polyvinyl pyrrolidone blended hydrogel for wound dressing. Radiat. Phys. Chem. 2001; 62, 107-13. 